UCRL-JC-121267

PREPRINT

\title{
Radiocarbon Dating of Ancient Rock Paintings
}

\author{
W.A. Ilger \\ M. Hyman \\ J. Southon \\ M.W. Rowe
}

This paper was prepared for submittal to the American Chemical Society Symposium on Archaeological Chemistry

Anaheim, $C A$

April 2-6, 1995

June 20, 1995

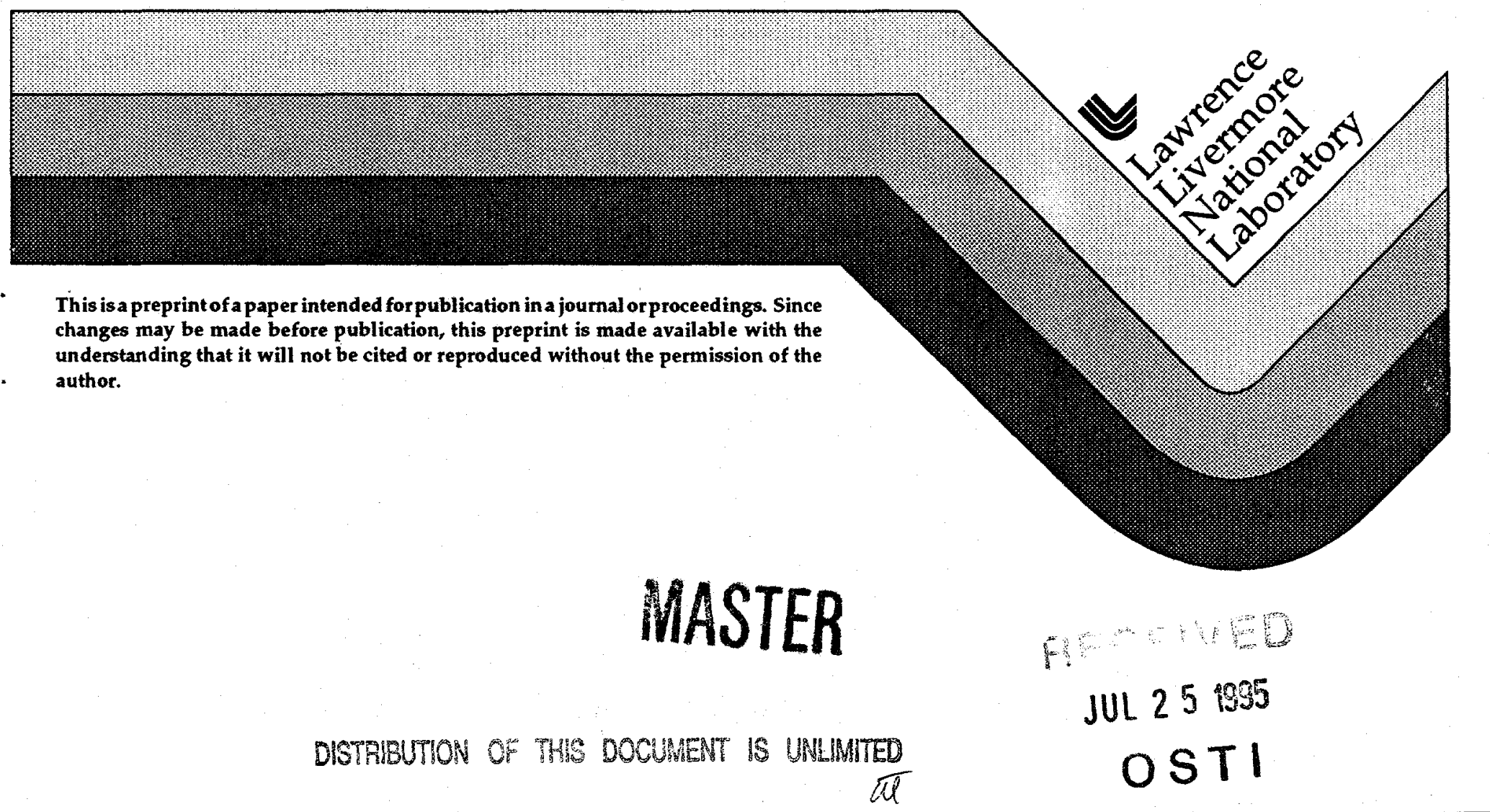




\section{DISCLAIMER}

Portions of this document may be illegible in electronic image products. Images are produced from the best available original document. 


\title{
Radiocarbon Dating of Ancient Rock Paintings
}

\author{
W. A. Ilger', M. Hyman', J. Southon ${ }^{2}$ and M. W. Rowe' \\ ${ }^{1}$ Department of Chemistry, Texas A\&M University, College Station, TX 77843, \\ USA \\ ${ }^{2}$ Center for Accelerator Mass Spectrometry, Lawrence Livermore National \\ Laboratory, Livermore, CA 94551-9900, USA
}

We report here progress on our technique for ${ }^{14} \mathrm{C}$ dating pictographs. We use lowtemperature oxygen plasmas coupled with high-vacuum technologies to selectively remove $\mathrm{C}$-containing material in the paints without contamination from inorganic carbon from rock substrates or accretions. Pictograph samples dated generally agree with ages expected on the basis of archaeological inference. We also used the technique on six samples of known ${ }^{14} \mathrm{C}$ activity. In each case our results agree with previously determined ages. Each of these determinations supports our conclusion that the technique has the potential of producing accurate and reliable ages. Four new ${ }^{14} \mathrm{C}$ dates were obtained on a quartered Pecos River style pictograph sample (41VV75-37A-D). We used an idealized model to estimate a lower limit for the age of the pictograph 41VV75-37. Although the measured "age" indicates that background organic material in the basal rocks and accretions can be a serious problem, the age itself should not be taken seriously as a meaningful limit.

\section{MASTER}


Traditionally, the study of prehistoric rock art has been marginal to mainstream American archaeological research. There are two primary reasons for this: (1) no rigorous models had been constructed for interpreting the art, or for integrating existing interpretations of it into larger reconstructions of prehistory; and (2) no means existed for directly dating the art. This situation began to change during the past decade. Recent trends suggest, in fact, that rock art research now may be at the theoretical and methodological forefront in archaeological studies of hunter-gatherers, providing information not accessible using traditional excavation and settlement pattern data (l). The second concern, the ability to relate rock art on cave and shelter walls to other archaeological remains, is addressed partially in this paper.

Tandem accelerator mass spectrometry (AMS) greatly reduced the amount of carbon necessary to obtain a ${ }^{14} \mathrm{C}$ date $(2-4)$ and encouraged attempts to date rock art around the world. Van der Merwe et al. (5) were first to date a charcoal pigment from a pictograph; others soon followed, also dating charcoal pigments (6-13). As with any archaeological charcoal, caution must be exercised when interpreting charcoal-derived ${ }^{14} \mathrm{C}$ dates due to the "old wood problem"; but otherwise no special problems appear to attend dating of pictograph charcoal. However, inorganic pigments are used far more frequently for pictograph pigments than is charcoal. Iron- and manganese- oxides and hydroxides are the most common pigments and these cannot be dated directly. Nonetheless, if ancient painters added organic materials as binders or vehicles to their inorganic pigments, this organic carbon can be ${ }^{14} \mathrm{C}$ dated. In 1990 , we introduced a plasmachemical technique to date pictographs, even those that used inorganic pigments (14). We have tested our method by determining ${ }^{14} \mathrm{C}$ in samples of known activity: ${ }^{14} \mathrm{C}$-free Albertite; ${ }^{14} \mathrm{C}$-free IAEA and Axel Heiberg wood; our determinations on these ${ }^{14} \mathrm{C}$-free samples showed that we were not introducing significant modern carbon with our technique. We have also studied previously dated charcoal and Third International Radiocarbon Intercomparison (TIRI) wood (Figure 1). Our dates agree with the previous ages on charcoal (Beta Analytic, Inc. and University of Texas Radiocarbon Laboratory) and TIRI wood. In all but one case, our measured dates agree within 
one standard deviation with those reported earlier. In the other case, the agreement is at the two standard deviation level. These measurements support the general validity of the technique.

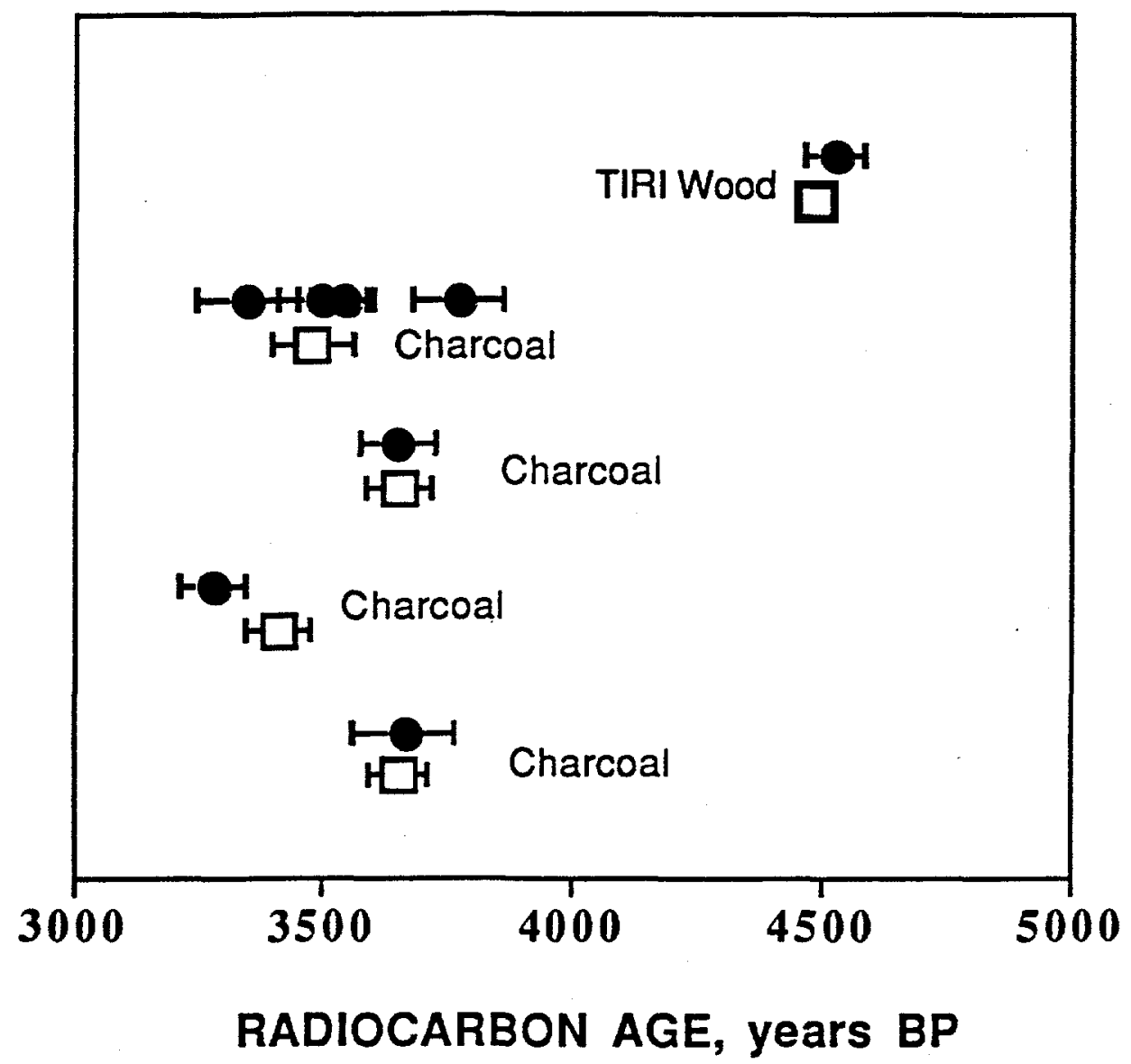

Figure 1. Comparison of our results with previously determined ages on TIRI wood and four charcoal samples. Symbols: our measurements; $\square$ known age.

Pictographs painted with inorganic pigments can therefore be dated with our technique. But to do so with accuracy and reliability requires that the following conditions be met: (1) organic matter was added initially to the paints as binder or vehicle and enough of the organic material has survived to yield a sufficiently large carbon sample; (2) organic carbon can be extracted without contamination from either atmospheric, or inorganic carbon often found, either as limestone $\left(\mathrm{CaCO}_{3}\right.$ and $\left.\mathrm{MgCO}_{3}\right)$, or in mineral accretions as carbonates and oxalates found both below and 
above the pictograph; (3) the technique used does not introduce significant mass fractionation that would influence the ${ }^{14} \mathrm{C}$ date; (4) carbon originally added to the paint does not exchange with other sources of carbon after paint was applied; and (5) the basal rock of the pictographs, and the associated mineral accretions do not contain enough organic material (contamination) to invalidate the date.

Our previous work (14-20) demonstrates that condition (1) is met for most, but not all, pictographs we have studied. Conditions (2) and (3) are well met with the plasma-chemical technique introduced in our laboratory in $1990(19,20)$. Evaluating how well condition (4) is met is more difficult. Ten pictograph dates have been obtained which can be compared with the large age ranges inferred from archaeology. Archaeological inferences giving the expected age ranges for Pecos River, Red Linear and Red Monochrome styles have been discussed by us elsewhere (15). Measured ages generally fall in the ranges expected. Similarly, pictographs from Utah (All American Man) and Montana agree with archaeologically expected ages; they also were discussed elsewhere $(13,16)$. The general agreement of our dates with inferred ages based on archaeological information implies that there is not large scale exchange of pictograph binder or vehicle organic carbon with extraneous carbon from carbonates, oxalates, ground water or the atmosphere; thus, condition (4) is probably met, although further study is needed. We are currently conducting experiments to determine the source of the binder or vehicle used in the paint of two Pecos River style pictographs from Seminole Canyon, Texas site, 41VV75 (21). Using DNA phylogenetic analysis, our work shows that even-toed hoofed mammalian (Order Artiodactyla) organic matter was incorporated into the paints. Once the exact nature of the carbonaceous matter being dated is established, strict validity of condition (4) can be evaluated in detail.

Condition (5) is often violated in our experience. Contamination levels we have found range from insignificant to a level such that background unpainted samples yield carbon in amounts comparable to painted samples. In each of two approaches to correct for background contamination (15), reasonable ages resulted. Unfortunately, archaeologically inferred age ranges are too broad to provide stringent tests of corrections, or of the technique in general. In order to 
address reproducibility of the materials normally sampled for a pictograph date and reproducibility of AMS for pictograph samples, we subjected each section of a quartered Pecos River style pictograph sample to our plasma-chemical extraction technique for ${ }^{14} \mathrm{C}$ dating.

\section{Experimental Method}

Our technique is based on the selective extraction of carbon from any organic binder or vehicle used in the pictograph. For that purpose we chose O-plasmas (14). As many samples are painted on largely inorganic carbon-containing materials, e.g., limestone, it is essential that the plasma not convert these materials to $\mathrm{CO}_{2}$; therefore low temperatures are required. Temperature during plasma operation was determined as follows: a 1 torr O-plasma was maintained for 30 minutes; the radio frequency (RF) power was turned off and the temperature recorded for 15 minutes. Figure 2 shows a temperature vs. time plot; temperatures at time zero were found using linear regression. Thus at 50,100 , and 150 watts at 1 torr of $\mathrm{O}_{2}$, the chamber was heated to 80,125 , and $150^{\circ} \mathrm{C}$,

respectively. Under these conditions, Chaffee, Hyman \& Rowe (19) reported no decomposition of either carbonates or oxalates.

We have built five systems since 1987; four are still in use. All are different in detail, but similar in principle. The following is a generic description of the systems. The glass reaction chamber is $\sim 10 \mathrm{~cm}$ in diameter and $\sim 20 \mathrm{~cm}$ long with two ports. One is for sample insertion, a second is connected to a glass manifold used to condense gases. $\mathrm{CO}_{2}$ extracted from a sample by an O-plasma is frozen, along with $\mathrm{H}_{2} \mathrm{O}$, in a liquid nitrogen cooled tube. Isolation of $\mathrm{CO}_{2}$ is accomplished by removing the liquid nitrogen and replacing it with an ethanol slurry at its melting point $\left(-117.3^{\circ} \mathrm{C}\right)$ to retain moisture, but release $\mathrm{CO}_{2}(\mathrm{~g}) . \mathrm{CO}_{2}$ is re frozen in another tube that is sealed off and sent to an AMS facility for ${ }^{14} \mathrm{C}$ dating. 


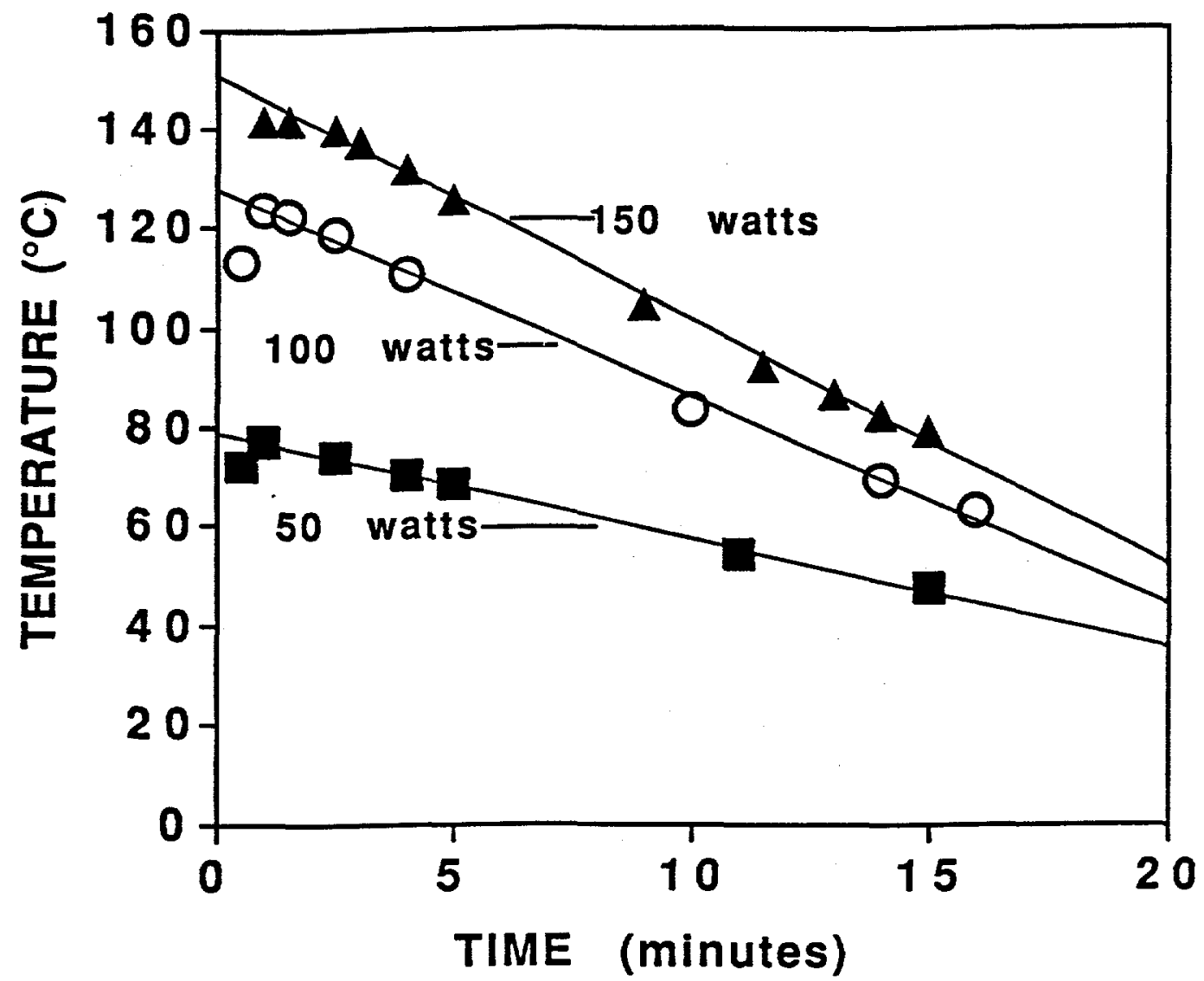

Figure 2. Extrapolation of time versus temperature for 50 watts $\left(\sim 80^{\circ} \mathrm{C}\right), 100$ watts $\left(-125^{\circ} \mathrm{C}\right)$, and 150 watts $\left(-150^{\circ} \mathrm{C}\right)$ to time zero.

Vacuum pumping is performed primarily by oil-free pumps, as even $\mu \mathrm{g}$ levels of contamination can affect ${ }^{14} \mathrm{C}$ results. An oil-based rotary pump is used occasionally to pump out two zeolite-filled sorption pumps through an oil trap. Sorption pumps are routinely used in series at liquid nitrogen temperature; one evacuates gas from atmospheric pressure (760 torr) to $\sim 10^{-5}$ torr; the second to $\sim 10^{-6}$ torr. When deemed necessary, sorption pump 1 is baked out to the rotary pump; sorption pump 2 is baked out onto sorption pump 1 cooled with liquid nitrogen. An ion pump maintains the chamber vacuum at $\sim 10^{-7}$ torr. Power is supplied by one of several RF generators. Typical operating powers are $<150$ watts. Current is passed to the chamber through external $\mathrm{Cu}$ electrodes. These connect to the power supply through a matching network. The matching network is adjusted to simultaneously maximize delivered power and minimize reflected 
power. Ultra-high purity $\mathrm{Ar}$ and $\mathrm{O}_{2}$ gases (99.999\%) are used. Gas lines are purged by bleeding to the atmosphere. A glass coil is attached to the gas inlet line, which is immersed in liquid nitrogen or an ethanol slurry during gas addition to freeze out condensable gas contaminants in $\mathrm{Ar}$ and $\mathrm{O}_{2}$. All-metal, bakeable valves are used in locations exposed to plasma as an O-plasma would attack any organic based gasket.

Gas lines are filled and evacuated three times after purging, and then evacuated to $\sim 200$ mtorr. Chamber pressure is adjusted to the following pressures for plasma generation: $0.5-1.0$ torr for $\mathrm{O}_{2}$ and 0.25-0.4 torr for Ar. Application of RF energy accelerates randomly occurring free electrons until they possess adequate energy to partially ionize the gas, thus generating additional free electrons. Under our conditions, probably less than $1 \%$ of the gas is ionized, with 10 to $20 \%$ of the $\mathrm{O}_{2}$ present as excited atoms. The end result of this is a plasma with low bulk temperature, $\leq 150^{\circ} \mathrm{C}$, and excited particles, electrons, ions, atoms and molecules sufficiently energetic to cause organic molecular bonds to break. In O-plasmas, virtually all organic materials are oxidized to $\mathrm{CO}_{2}$ and water.

Atmospheric $\mathrm{CO}_{2}$ adsorbed on surfaces inside the vacuum chamber would contaminate $\mathrm{CO}_{2}$ extracted from a sample. We first minimize this by heating the empty system and pumping away the $\mathrm{CO}_{2}$. Possible contamination of the empty sample chamber by either organic $\mathrm{C}$ or $\mathrm{CO}_{2}$ is further reduced prior to introduction of a sample by running several O-plasmas and pumping away the products. The first is run at 100 watts and 1 torr $\mathrm{O}_{2}$ for $\geq 1$ hour. This removes most contamination from the chamber. The second $\mathrm{O}$-plasma is run at 150 watts, and 0.5 torr of $\mathrm{O}_{2}$ which increases plasma temperature by a factor of $\sim 2(18)$. These conditions are more vigorous than those employed during sample oxidation, and efficiently clean the chamber. O-plasmas are typically repeated until $\mathrm{C}$ mass is $\sim 0.5 \mu \mathrm{g}$.

For sample insertion, we purge the line with $\mathrm{O}_{2}$, rather than $\mathrm{Ar}$ because the $\mathrm{Ar}$ response on the thermocouple pressure gauge maximizes at $\sim 2$ torr, even at atmospheric Ar pressure and above. $\mathrm{O}_{2}$ is bled into the chamber until the pressure is slightly above atmospheric. The sample port flange is removed only then to prevent contamination from atmosphere being drawn into the 
chamber. Chamber pressure will be high enough to gently force the blank flange away from the chamber. The sample is then placed in the chamber, and if powdered, spread out. The $\mathrm{Cu}$ gasket and flange are replaced and the $\mathrm{O}_{2}$ is evacuated. Depending on sample size and condition, it takes from 30 minutes to several days to transfer vacuum pumping from rough sorption pump to hard sorption pump to ion pump.

After heat is applied overnight or longer, we use Ar plasmas ( 0.4 torr) to bombard sample and chamber surfaces with excited atoms and ions of chemically inert $\mathrm{Ar}$ to assist desorption of $\mathrm{CO}_{2}$. Even a modest amount of atmospheric $\mathrm{CO}_{2}$ could cause error in the final result. In most cases, this combination of heat and Ar plasmas clean sample and chamber surfaces to the extent that $<1 \mu \mathrm{g} \mathrm{C}$ is generated from the final Ar plasma. Carbon masses are calculated using $\mathrm{CO}_{2}$ pressures and approximate system volumes.

A vacuum integrity check is performed before sample oxidation to verify that no appreciable leakage is occurring. This involves cessation of chamber pumping, and monitoring pressure rise over time. Usual times utilized for a vacuum integrity check are 2 hours, twice as long as the usual 1 hour or less used for sample oxidation plasmas. Final gas pressure determines the maximum amount of contamination introduced into the chamber in two hours. Vacuum integrity checks are shown in figure 3 for four samples of 41VV75-37. In the worst case for these samples, if all of the gas causing the temperature rise after an hour were $\mathrm{CO}_{2}$, the mass of the contamination would still be $\leq 0.2 \mu \mathrm{g} \mathrm{C}$, an insignificant amount, compared to typical backgrounds at AMS facilities at Lawrence Livermore National Laboratory (2 to $4 \mu \mathrm{g}$ of C) (Southon, J., Center for Accelerator Mass Spectrometry, Lawrence Livermore National Laboratory, Livermore, CA, personal communication, 1993), and at the University of Arizona ( 2 to $3 \mu \mathrm{g}$ of C) (Jull, A. J. T., NSF-Arizona AMS Facility, University of Arizona, Tucson, AZ, personal communication, 1993).

After completion of a vacuum integrity check, the sample is ready for oxidation. One torr of $\mathrm{O}_{2}$ is added to the chamber with liquid nitrogen kept on the glass coil. The O-plasma is run for one hour at 100 watts. After plasma termination, $\mathrm{O}_{2}$ is pumped from the chamber to $\sim 10^{-7}$ torr. The chamber is then isolated from pumps. $\mathrm{CO}_{2}$ is released from the cold finger by removal of 
liquid nitrogen; an ethanol slurry is applied to the cold finger to keep $\mathrm{H}_{2} \mathrm{O}$ frozen. The $\mathrm{PCO}_{2}$ is measured to calculate the weight of carbon. $\mathrm{CO}_{2}$ is then re frozen in another cold finger, sealed off, and sent to an AMS facility. An effort is made to generate a second portion of $\mathrm{CO}_{2}$, typically using 150 watts of $R F$ power. If an adequate mass of $C$ is generated, a second tube is sealed off and reserved for future studies. Standard plasma conditions used on pictograph samples are listed in Table I.

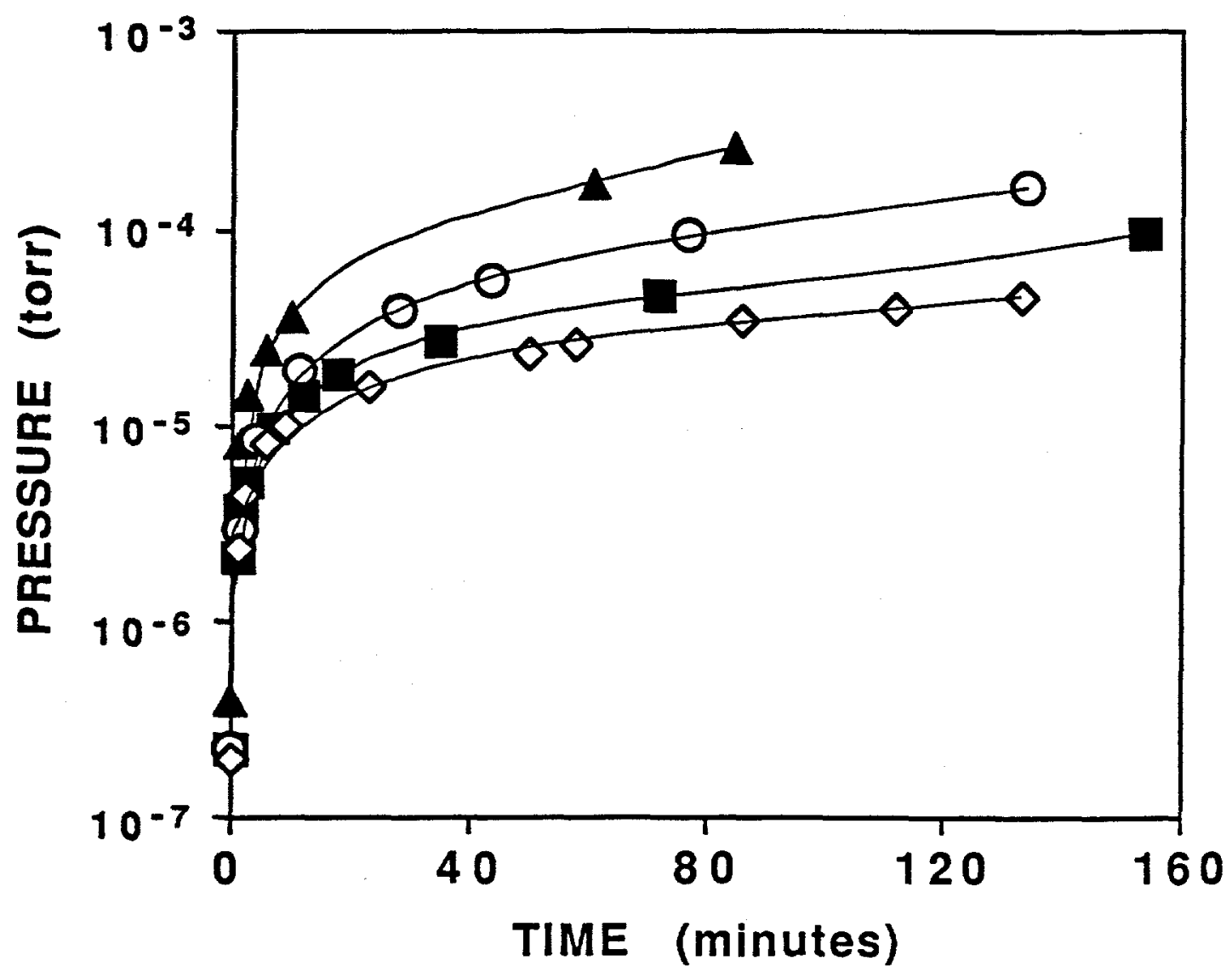

Figure 3. Vacuum integrity checks performed prior to oxidation of 41VV75-37A, B, $\mathrm{C}$ and $\mathrm{D}$. These curve fits were drawn using third order polynomials.

Symbols: O 41VV75-37A; O 41VV75-37B; A 41VV75-37C; 41VV75-37D.

Whenever possible, we now routinely study a matrix background of unpainted stone removed from the wall near the pictograph. This is to evaluate the extent of contamination from organic $\mathrm{C}$ not derived from pictograph pigment and to permit correction for that component. Both 
sampling and treatment are as nearly identical as possible. Calculations allowing for the effect of contaminant carbon on a pictograph ${ }^{14} \mathrm{C}$ result were discussed in an earlier paper (15).

\section{Table I. Plasma Types and Usual Conditions}

\begin{tabular}{llll}
\hline Plasma Purpose & Gas & $\begin{array}{l}\text { Pressure } \\
\text { (torr) }\end{array}$ & $\begin{array}{l}\text { Typical Power } \\
\text { (watts) }\end{array}$ \\
\hline Initial empty chamber cleaning & $\mathrm{O}_{2}$ & 1.0 & 100 \\
Subsequent empty chamber cleanings & $\mathrm{O}_{2}$ & 0.5 & 150 \\
Sample and chamber cleanings & $\mathrm{Ar}$ & 0.4 & $25-40$ \\
Sample oxidation \#1 & $\mathrm{O}_{2}$ & 1.0 & 100 \\
\hline
\end{tabular}

\section{Results and Discussion}

Replicate Analyses of a Pecos River Style Pictograph, 41VV75-37. The pictograph we selected for this study was removed from site 41 VV75 in the Lower Pecos River, Texas region, a site where natural spallation has resulted in loss of over $50 \%$ of the panel sampled. We collected a piece, $\sim 5 \times 7 \mathrm{~cm}$, and divided it approximately into quarters. After ultrasonicating the sample in doubly distilled, deionized $\mathrm{H}_{2} \mathrm{O}$, we scraped off two opposite quarters from the stone backing, attempting to remove only accretion and pigment layers from the limestone substrate. We processed these quarters separately to investigate reproducibility obtainable by dating different portions of a pictograph (41VV75-37A and B). The remaining two quarters were removed from the stone backing, combined, and homogenized by four quartering it ten times on a small sheet of $\mathrm{Al}$ foil. This mixed pigment and accretion was then divided approximately in half, each of which was processed separately to study AMS reproducibility on pictograph material. These two portions were identified as 41 VV75-37C and D.

The color of the pigment with accretion mixture A was between Munsell pinkish gray to pinkish white, notation 5YR 7.5/2 (23). The pigment in a polished section viewed through a 
microscope was far redder (Munsell dark red, 10R 3/6), but accretion mixed with the pigment layer diluted the red hematite color. Pigment and accretion layers were removed as quarter B from the surface of the stone backing opposite quarter A. This second quarter (B) was redder (Munsell color pink, and notation 5YR 7/3) than other quarters from this pictograph. The color of sample C was indistinguishable from $\mathrm{D}$ due to homogenization. The combined mixture samples, 41VV7537C and D were Munsell pinkish gray, notation 5YR 7/2.

After completing plasma cleaning of the chamber, we subjected each sample to the plasma extraction procedure. Table II sets forth details of plasmas used to process these four samples.

Table II. Plasmas Performed for Chamber Cleaning and Sample Processing of 41VV75-37A, B, C and D

\begin{tabular}{|c|c|c|c|c|}
\hline $\begin{array}{l}\text { Samplel } \\
\text { Plasma Gas }\end{array}$ & Plasma Purpose & $\begin{array}{l}\text { RF Power } \\
\text { (watts) }\end{array}$ & $\begin{array}{l}\text { Final Plasma } \\
\text { Duration (min) }\end{array}$ & $\begin{array}{l}\text { Final Mass } \\
\text { Carbon }(\mu g)\end{array}$ \\
\hline \multicolumn{5}{|l|}{$\frac{41 V V 75-37 A}{\mathrm{O}_{2}}$} \\
\hline $\begin{array}{l}\mathrm{O}_{2} \\
\mathrm{Ar}\end{array}$ & $\begin{array}{l}\text { chamber cleaning } \\
\text { sample and } \\
\text { chamber cleaning }\end{array}$ & $\begin{array}{l}100-150 \\
30\end{array}$ & $\begin{array}{l}65 \\
240\end{array}$ & $\begin{array}{l}0.08 \\
1.2\end{array}$ \\
\hline $\begin{array}{l}\mathrm{O}_{2} \\
\mathrm{O}_{2}\end{array}$ & $\begin{array}{l}\text { sample oxidation } \\
\text { sample oxidation }\end{array}$ & $\begin{array}{l}100 \\
150\end{array}$ & $\begin{array}{l}62 \\
62\end{array}$ & $\begin{array}{l}715 \\
330\end{array}$ \\
\hline \multicolumn{5}{|l|}{$4 I V V 75-37 B$} \\
\hline $\begin{array}{l}\overline{\mathrm{O}_{2}} \\
\mathrm{Ar}\end{array}$ & $\begin{array}{l}\text { chamber cleaning } \\
\text { sample and } \\
\text { chamber cleaning }\end{array}$ & $\begin{array}{l}100-150 \\
30\end{array}$ & $\begin{array}{l}110 \\
60\end{array}$ & $\begin{array}{l}0.3 \\
5\end{array}$ \\
\hline $\begin{array}{l}\mathrm{O}_{2} \\
\mathrm{O}_{2}\end{array}$ & $\begin{array}{l}\text { sample oxidation } \\
\text { sample oxidation }\end{array}$ & $\begin{array}{l}100 \\
150\end{array}$ & $\begin{array}{l}62 \\
62\end{array}$ & $\begin{array}{l}870 \\
650\end{array}$ \\
\hline \multicolumn{5}{|l|}{$41 V V 75-37 C$} \\
\hline $\begin{array}{l}\overline{\mathrm{O}_{2}} \\
\mathrm{Ar}\end{array}$ & $\begin{array}{l}\text { chamber cleaning } \\
\text { sample and } \\
\text { chamber cleaning }\end{array}$ & $\begin{array}{l}100-150 \\
30\end{array}$ & $\begin{array}{l}60 \\
135\end{array}$ & $\begin{array}{l}0.2 \\
6\end{array}$ \\
\hline $\begin{array}{l}\mathrm{O}_{2} \\
\mathrm{O}_{2}\end{array}$ & $\begin{array}{l}\text { sample oxidation } \\
\text { sample oxidation }\end{array}$ & $\begin{array}{l}100 \\
150\end{array}$ & $\begin{array}{l}62 \\
62\end{array}$ & $\begin{array}{l}730 \\
330\end{array}$ \\
\hline \multicolumn{5}{|l|}{$4 I V V 75-37 D$} \\
\hline $\begin{array}{l}\overline{\mathrm{O}_{2}} \\
\mathrm{Ar}\end{array}$ & $\begin{array}{l}\text { chamber cleaning } \\
\text { sample and } \\
\text { chamber cleaning }\end{array}$ & $\begin{array}{l}100-150 \\
30\end{array}$ & $\begin{array}{l}75 \\
60\end{array}$ & $\begin{array}{l}0.9 \\
1.2\end{array}$ \\
\hline $\begin{array}{l}\mathrm{O}_{2} \\
\mathrm{O}_{2}\end{array}$ & $\begin{array}{l}\text { sample oxidation } \\
\text { sample oxidation }\end{array}$ & $\begin{array}{l}100 \\
150 \\
\end{array}$ & $\begin{array}{l}62 \\
60\end{array}$ & $\begin{array}{l}960 \\
420 \\
\end{array}$ \\
\hline
\end{tabular}


${ }^{14} \mathrm{C}$ results returned from Lawrence Livermore National Laboratory Center for Accelerator Mass Spectrometry (CAMS), as well as calibrated age ranges for this series are listed in Table III. Samples 41VV75-37C and D demonstrate AMS reproducibility of two homogenized opposite quarters of the same pictograph. The ages are statistically indistinguishable. The average age of pictograph quarters $\mathrm{C}$ and $\mathrm{D}$ homogenized pigment is 3225 years $\mathrm{BP}$, while the average age of the first two pictograph quarters is 3265 years BP. Thus, the average age of portions A and B is statistically indistinguishable from the average age of homogenized pigment and accretion mixture $\mathrm{C}$ and $\mathrm{D}$ as well.

Table III. Results and calibration of ${ }^{14} \mathrm{C}$ ages on Pecos River style pictograph at 41VV75-37A-D

\begin{tabular}{llll}
\hline $\begin{array}{l}\text { 4IVV75-37 } \\
\text { Quarter }\end{array}$ & CAMS Sample I. D. & ${ }^{14}$ C Years $(B P)^{a}$ & ${ }^{14}$ C Years $(B P)^{b}$ \\
\hline A & CAMS-14087 & $2950 \pm 60$ & $3240-2960$ \\
B & CAMS-14088 & $3580 \pm 60$ & $3960-3730$ \\
C & CAMS-14089 & $3240 \pm 60$ & $3550-3360$ \\
D & CAMS-14090 & $3210 \pm 60$ & $3470-3360$ \\
\hline
\end{tabular}

aFrom LLNL

bCalibrated results were calculated by the program of Stuiver and Reimer (24). These results are $1 \sigma$ age ranges, as calculated using method $A$ for each of the four experiments.

As previously mentioned, we ran opposite quarters A and B of the Pecos River style pictograph separately without homogenization; their AMS ages were different by 630 years. The colors of the two pigment and accretion powders, $\mathrm{A}$ and $\mathrm{B}$, were also different from each other and from the C-D color. The pigment with accretion mixture 41VV75-37B was redder than 41VV75$37 \mathrm{~A}$, indicating that $\mathrm{B}$ has a larger fraction of pigment, and thus implying a higher proportion of organic binder or vehicle, than A. Portions C-D were intermediate in color between A and B. Since $B$, the pigment-enriched sample generated the oldest ${ }^{14} \mathrm{C}$ age, it follows that organic carbon in the pictograph is older than that of contamination carbon in the accretion. Mixing the pigment layer with overlying accretion generates a composite ${ }^{14} \mathrm{C}$ date consisting of organic $\mathrm{C}$ from both 
sources. Differences in ages between three results (A, B and C-D) are presumably due to a variation of the proportion of organic carbon from pictograph and accretion layers in the samples.

By utilizing differences in ages, we can limit ranges of possible ages of both pictograph and accretion. These limits are based on quarters $\mathrm{A}$ and $\mathrm{B}$, as they exhibited the largest differences in age; inclusion of C-D would not affect the arguments. Two basic assumptions are used in these idealized model calculations. First, ages of both accretion and pictograph are assumed to be constant over the area sampled. Presumably this is true for the organic material that had been added to the paint, but it is far less likely to be true for the accretion, which may well vary in age from paint to paint on the pictograph. Second, ${ }^{14} \mathrm{C}$ activities reported from the AMS are assumed to be a weighted average of ${ }^{14} \mathrm{C}$ activities of accretion and pictograph organic materials. This assumption is probably valid by definition, since we are combining all non-paint organic matter into accretion. With these assumptions, we can write for each sample:

$$
a_{m}=X a_{p}+(1-X) a_{a}
$$

where $a_{m}$ is ${ }^{14} \mathrm{C}$ activity of a mixture of pictograph pigment layer and accretion, $a_{p}$ is ${ }^{14} \mathrm{C}$ activity of the pictograph itself, $a_{a}$ is ${ }^{14} \mathrm{C}$ activity of accretion, and $X$ is the fraction organic $C$ in the pigment layer from the pigment and accretion mixture. ${ }^{14} \mathrm{C}$ activities of the first two quarters are 0.6926 (2950 years BP) and 0.6404 (3580 years BP), so that

$$
\begin{aligned}
& 0.6926=X_{A} a_{p}+\left(1-X_{A}\right) a_{a} \\
& 0.6404=X_{B} a_{p}+\left(1-X_{B}\right) a_{a}
\end{aligned}
$$

where $X_{A}$ represents the fraction of organic $C$ in pigment from the pigment with accretion mixture for 41VV75-37A, and $X_{B}$ represents the same fraction for 41VV75-37B. We now have two equations with four unknowns $\left(a_{p}, a_{a}, X_{A}\right.$ and $\left.X_{B}\right)$, so a unique solution is not possible. Addition 
of the other two quarters does not help as two additional unknowns are added with each equation.

We can, however, use equations 2 and 3 to limit possible extreme values of $X_{A}$ and $X_{B}$, that in turn can be used to constrain possible ${ }^{14} \mathrm{C}$ ages of both pictograph and accretion. We use maximum and minimum possible values for $\mathrm{a}_{\mathrm{p}}$ and $\mathrm{a}_{\mathrm{a}}$. As maximum and minimum values for activity are 1 and 0 , it follows that if $a_{a}$ is assumed to be modern (1), and $a_{p}$ is assumed to be ancient (0), we can calculate maximum limiting values for both $\mathrm{X}_{\mathrm{A}}$ and $\mathrm{X}_{\mathrm{B}}$ using equations 2 and 3. Conversely, if then $a_{p}$ is assumed to be ancient (0), and $a_{a}$ is assumed to be modern (1), another limiting set of $X_{A}$ and $X_{B}$ values are generated. These possible $X$ values are shown in Table IV.

Table IV. Limiting Values of $X$, Based on Maximum and Minimum Values of Activity for Pictograph and Accretion

\begin{tabular}{llll}
\hline$a_{b}$ & $a_{a}$ & $X_{A}$ & $X_{B}$ \\
\hline 1 & 0 & $0.6926^{\mathrm{a}}$ & 0.6404 \\
0 & 1 & 0.3074 & 0.3596 \\
\hline
\end{tabular}

aAlthough this is the maximum value of $\mathrm{X}_{\mathrm{A}}$ based solely on activities, the additional constraint that $\mathrm{X}_{\mathrm{B}}>\mathrm{X}_{\mathrm{A}}$ restricts $\mathrm{X}_{\mathrm{A}}$ further to $<0.6404$.

Based on our observation that the color of the pigment and accretion mixture for quarter B is redder than the mixture for quarter $A$, for any given pair of $X_{A}$ and $X_{B}$ values selected, we assume that $\mathrm{X}_{\mathrm{B}}>\mathrm{X}_{\mathrm{A}}$. There are three extreme cases to which we can apply $\mathrm{X}$ values in Table IV; first is the use of the maximum allowable value for $\mathrm{X}_{\mathrm{B}}$ and the minimum value of $\mathrm{X}_{\mathrm{A}}$. The second uses the largest allowable value of $\mathrm{X}_{\mathrm{B}}$, in combination with the largest possible value of $\mathrm{X}_{\mathrm{A}}$ (remembering that $\mathrm{X}_{\mathrm{B}}$ must be greater than a given $\mathrm{X}_{\mathrm{A}}$ ). The third case uses minimum allowable values for $\mathrm{X}_{\mathrm{B}}$ and $\mathrm{X}_{\mathrm{A}}$, again with $\mathrm{X}_{\mathrm{B}}>\mathrm{X}_{\mathrm{A}}$. Of these, only the first yields useful information; cases 2 and 3 will be discussed briefly below.

Thus, using case 1 values for $X_{A}$ and $X_{B}$ which differ to the greatest extent possible, e.g. 0.3074 for $\mathrm{X}_{\mathrm{A}}$ and 0.6404 for $\mathrm{X}_{\mathrm{B}}$, we get simultaneous equations 4 and 5 below. 


$$
\begin{aligned}
& 0.6926=0.3074 a_{p}+(1-0.3074) a_{a} \\
& 0.6404=0.6404 a_{p}+(1-0.6404) a_{a}
\end{aligned}
$$

Solution of these equations yields activities of 0.7408 for $a_{a}$, and 0.5840 for $a_{p}$, which can then be converted to ages of 2410 years BP for the accretion and 4320 years BP for the pictograph. Thus the maximum age possible for the accretion is 2410 years BP while the minimum age for the pictograph is 4320 years BP. These ages should not be taken as meaningful limits. Rather they point out that the measured ages may be several hundreds of years from the "true", i.e., uncontaminated age. It is clear that a practicable means for dealing with the effect of contamination is needed. The maximum $\mathrm{X}_{\mathrm{A}}$ and the minimum $\mathrm{X}_{\mathrm{B}}$ are not selected as that violates the condition that $\mathrm{X}_{\mathrm{B}}>\mathrm{X}_{\mathrm{A}}$. It is difficult to limit the upper end of the possible age range for the pictograph. Application of case 2, the largest allowable $\mathrm{X}_{\mathrm{A}}$ and $\mathrm{X}_{\mathrm{B}}$ combinations, and case 3, minimum allowable $\mathrm{X}_{\mathrm{A}}$ and $\mathrm{X}_{\mathrm{B}}$ values, does not lead to useful maximum and minimum limits on pictograph and accretion ages, respectively. Without knowing the accretion age, cases 2 and 3 yield possible pictograph ages of 10,000 years BP and above, which are excessively ancient. Further constraint of this range at the upper end is possible with additional data. If accretion is assumed to deposit at a constant, uniform rate after the pictograph was painted, incorporating ambient $\mathrm{CO}_{2}$ as it grows, then the age of the accretion would be one-half the time that has elapsed since the pictograph was painted. This would then place the pictograph age at 4820 years BP. Thus, with this simple, idealized model, our estimate for the age of pictograph 41VV75-37, though not well constrained at the older end, lies between 4320 and 4820 years BP. However, as this age range is based on questionable assumptions, it is probably not meaningful.

Taken at face value, $\mathrm{X}$-values we arrived at with the idealized model indicate that a significant fraction of the organic $\mathrm{C}$ present in the sample is due to contamination in this pictograph. Percent contamination is represented by $(1-\mathrm{X}) \times 100,69.3 \%$ organic $\mathrm{C}$ contamination of 41VV75-37A, and 36\% organic C contamination of 41VV75-37B for the limiting case we 
discussed. Because of these results, we will, in the future, change our procedure to remove as much accretion as possible prior to removal of the pigment layer. Both physical and chemical methods for reducing contamination will be investigated. Smaller amounts of accretion would not present such a significant contamination problem, and could be adequately corrected for. At 10$20 \%$ levels of contamination, reasonable corrections can be made with confidence and tolerably small uncertainty (15).

Evidence derived from the four samples of $41 \mathrm{VV} 75-37$ indicates that background contamination may introduce substantial uncertainty to the dating of Pecos River style pictographs. An improvement is possible if values of $\mathrm{X}_{\mathrm{A}}$ and $\mathrm{X}_{\mathrm{B}}$, or even the ratio, $\mathrm{X}_{\mathrm{B}} / \mathrm{X}_{\mathrm{A}}$, could be obtained. If $X_{A}$ and $X_{B}$ were known, equations 2 and 3 could be solved uniquely for $a_{p}$ and $a_{a}$, thus getting the ages of both the pictograph and accretion directly. This, however, rests on the ability to determine $\mathrm{X}_{\mathrm{A}}$ and $\mathrm{X}_{\mathrm{B}}$, or the organic content of the pictograph layer/accretion ratio for each age determination. As we can think of no way to make those measurements, it does not appear to us to be a practicable solution to the contamination problem at this time.

\section{Conclusions}

We have found that the variability of the background contamination in a single Pecos River style pictograph sample on a few $\mathrm{cm}$ scale is appreciable, corresponding to a radiocarbon age difference of 630 years for adjacent samples. Even with utmost care in selecting unpainted background rock to correspond closely to the pictograph samples taken, uncertainties of several centuries may be unavoidable when the magnitude of the background is over 10-20\% using the correction methods suggested earlier (15). The problem could be solved if (1) a means for determining the fraction $\left(\mathrm{X}_{\mathrm{a}}\right.$ and $\left.\mathrm{X}_{\mathrm{b}}\right)$ of contamination-organic-carbon to pictograph-organic-carbon could be found and (2) by measuring two samples of the same pictograph and solving equations (2) and (3) simultaneously, which seems unlikely. Because we are unable to measure $X_{a}$ and $X_{b}$ directly, we will examine both physical and chemical means of removing the contamination from the sample as 
an alterative approach. This study underscores the need for extreme care in sample and background collection and their subsequent analyses, as well as a suitable means of dealing with contamination. Based on the findings from these quartered samples, previously reported ages for Pecos River style pictographs from our group (summarized in 14) may be better thought of as minimum ages; it is likely that contamination is younger than the paint.

We remain cautiously optimistic that pictographs painted with inorganic pigments can be dated directly using the plasma-chemical treatment followed by AMS radiocarbon determinations. Some situations, as the one described here for Pecos River style pictographs, 41VV75-37A-D, require more extreme measures than have been routine in our laboratory before adequately accurate and reliable ages can be obtained.

\section{Acknowledgments}

We are grateful to the following for partial support: Research Corporation Grant R-157; Donors of Petroleum Research Fund Grant ACS-PRF 20252-AC8 administered by the American Chemical Society; and Robert A. Welch Foundation Grant A-1235. Ruth Ann Armitage permitted us to include some of her data in Figure. 1. Bęth Shapiro assisted with some of the calculations. This work was performed under the auspices of U.S. DOE by LINL under contract W-7405-Eng-48.

\section{Literature Cited}

1. Whitley, D. S. and Loendorf, L. L. In New Light on Old Art: Recent Advances in HunterGatherer Rock Art, Whitley, D. S. and Loendorf, L. L., Eds.; Monogram 36; UCLA Institute of Archaeology; University of California Press: Los Angeles, 1994; pp xi-xx.

2. Bennet, C. L.; Beukens, R. P.; Clover, M. R.; Gove, H. E.; Lievert, R. B.; Litherland, A. E.; Purser, K. H.; Sondheim, W. E. Science 1977, 198, 508-509.

3. Nelson, D. E.; Kortling, R. G.; Stott, W. R. Science 1977, 198, 507-508.

4. Muller, R. A.. Science 1977, 196, 489-494.

5. Van der Merwe, N. J.; Sealy, J.; Yates, R. South African Journal of Science 1987, 83, 5657.

6. McDonald, J.; Officer, K.; Donahue, D.; Head, J.; Ford, B. Rock Art Research 1990, 7, 8392.

7. Valladas, H.; Cachier, H.; Arnold, M. Rock Art Research 1990, 7, 18-19.

8. Farrell, M.; Burton, J. North American Archaeologist 1992, 13, 219-247.

9. Geib, P.; Fairley, H. Journal of Field Archaeology 1992, 19, 155-168.

10. Valladas, H.; et al. Nature 1992, 357, 68-70.

11. Clottes, J.; Courtin, J.;Valladas, H. Rock Art Research 1992, 9, 122-123.

12. David, B. Rock Art Research 1992, 9, 139-141.

13. Chaffee, S.; Hyman, M.; Rowe, M. W.; Coulam, N.; Schroedl, A.; Hogue, K. American Antiquity 1994, 59, in press.

14. Russ, J.; Hyman, M.; Shafer, H. J.; Rowe, M. W. Nature 1990, 348, 710-711.

15. Iner, W.; Hyman, M.; Rowe, M. W. Radiocarbon 1994, in press.

16. Chaffee, S. D.; Loendorf, L. L.; Hyman, M.; Rowe, M. W. Plains Anthropologist 1994, 39, 195-201.

17. Russ, J.; Hyman, M.; Shafer, H. J.; Rowe, M. W. Plasma Chemistry \& Plasma Processing $1991,11,515-527$. 
18. Russ, J.; Hyman, M.; Rowe, M. W. Radiocarbon 1992, 34, 867-872.

19. Chaffee, S.; Hyman, M.; Rowe, M. W. In Time and Space: Dating and Spatial Considerations in Rock Art Research, Steinbring, J.; Watchman, A.; Faulstich, P.; Taçon, P., Eds.; Occasional Publication No. 8, Australian Rock Art Research Association: Caulfield, Australia, 1993, pp 67-73.

20. Chaffee, S.; Hyman, M.; Rowe, M. W. In New Light on Old Art: Recent Advances in Hunter-Gather Rock Art Research; Whitley, D. S. and Loendorf, L. L., Eds.; Monograph 36; UCLA Institute of Archaeology; University of Califomia Press: Los Angeles, 1994; pp 9-12.

21. Reese, R. L.; Derr, J.; Hyman, M.; Rowe, M. W.; Davis, S. J. Archaeological Science, 1995 , in press.

22. Mawk, E. J.; Reese, R. L.; Derr, J.; Hyman, M.; Rowe, M. W.; Davis, S. This volume 1994, Chap. Z, xxx-yyy.

23. Munsell Soil Color Charts 1975, MacBeth Division of Kollmorgen Corporation, Baltimore, MD.

24. Stuiver, M.; P. J. Reimer Radiocarbon 1993, 35, 215-230. 